
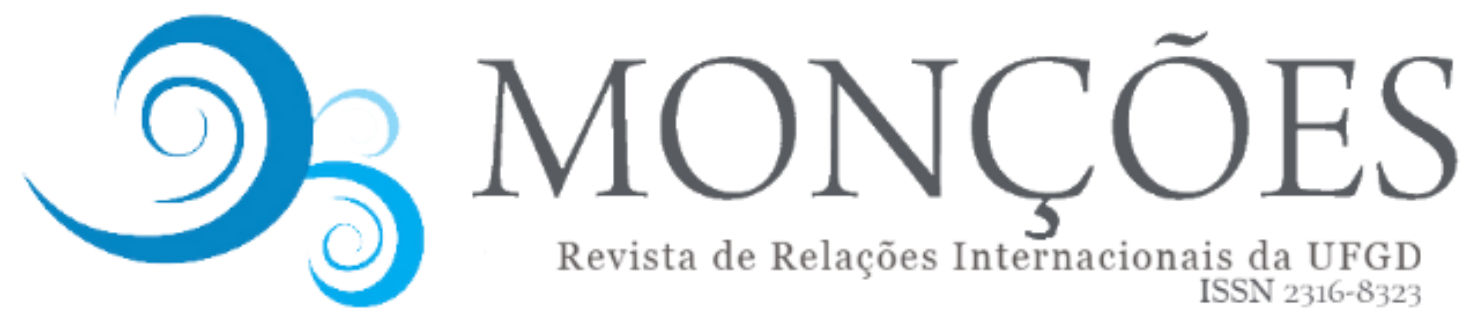

ISSN $2316-8323$

\title{
ESCRAVISMO ATLÂNTICO NO SÉCULO XIX: A CONSTRUÇÃO DO "INTERNACIONAL" NO MAR"
}

\begin{abstract}
GUSTAVO ALVIM DE GÓES BEZERRA
Servidor Público no MPRJ e doutorando em Relações Internacionais pela PUC-Rio, é mestre em Relações Internacionais pela UERJ. E-mail: gusgbezerra@gmail.com

PEDRO SALGADO

Pesquisador Pós-Doutoral em Relações Internacionais pela Universidade Federal de Uberlândia e professor no Centro Universitário de Patos de Minas Universidade. É mestre e doutor em Relações Internacionais pela Universidade de Sussex. E-mail:

pedro.salgado@ufu.br

ROBERTO VILCHEZ YAMATO

Professor do IRI/PUC-Rio. Doutor em Relações Internacionais pelo IRI/PUC-Rio. Doutorando em Direito, Birkbeck, University of London. Mestre em Ciências Sociais/Relações Internacionais pela PUC-SP. Mestre em Direitos Humanos pela (LSE). E-mail:

roberto.v.yamato@gmail.com
\end{abstract}

\begin{abstract}
RESUMO: Este artigo almeja trazer o comércio transatlântico de pessoas escravizadas para o centro do debate historiográfico e teórico das Relações Internacionais, em particular no que tange à formação e evolução do sistema internacional de Estados soberanos. Tal movimento se dá fundamentalmente em dois passos. Em um primeiro momento, promovemos uma discussão nos termos da Escola Inglesa, como tradição teórica que se debruça sobre a evolução histórica da política internacional. Demonstramos, com esse engajamento crítico, o silenciamento da disciplina para a escravização transatlântica como uma "instituição fundamental" da "sociedade internacional". No segundo momento, avaliamos as consequências teóricas da inclusão do comércio e exploração do trabalho de pessoas no rol de instituições fundamentais que formam a sociedade internacional. Questionamos se tal inclusão é suficiente para desfazer o que identificamos como "silêncio constitutivo" que a escravidão atlântica representa para a disciplina e se a inclusão desta instituição internacional reforma as premissas eurocêntricas sobre as quais se baseia a Escola Inglesa. A partir daí, propomos uma reflexão epistemológica sobre a historiografia das Relações Internacionais que aponta para um diálogo mais profundo entre teoria e história, a partir de evoluções recentes nos campos da Sociologia Histórica e dos estudos Pós/Decoloniais.
\end{abstract}

PALAVRAS-CHAVE: Escravização atlântica; Sociologia Histórica; Estudos Pós- e Decoloniais.

\footnotetext{
${ }^{1}$ O presente trabalho foi realizado com apoio da Coordenação de Aperfeiçoamento de Pessoal de Nível Superior - Brasil (CAPES) - Código de Financiamento 001
} 


\begin{abstract}
This paper aims to bring the transatlantic trade of enslaved people to the centre of the historical and theoretical debates in IR, especially those regarding the formation and evolution of the international system of sovereign states. This movement takes place in two fundamental steps. Firstly, we promote this discussion within the terms provided by the English School, as the theoretical tradition that is more openly dedicated to the historical evolution of international politics. We demonstrate, through this critical engagement, the disciplinary silence about transatlantic enslavement as a "primary institution" of "international society". In a second moment, we evaluate the theoretical consequences of including the trade in human beings and the exploitation of their coerced labor among the primary institutions that shape international Society. We question whether such inclusion is sufficient to unmake the "constitutive silence" represented by Atlantic slavery in the discipline, and whether this inclusion effectively reforms the Eurocentric premises of the English School. From these questions, we offer an epistemological reflection on the historiograhpy of IR that points toward a deeper dialogue between history and theory, building upon recent developments on the literatures on Historical Sociology and Post-/Decolonial thought.
\end{abstract}

KEYWORDS: Atlantic slavery; Historical Sociology; Post- and Decolonial Studies.

\title{
1. Introdução
}

Debates historiográficos recentes trouxeram novas perspectivas sobre a experiência de escravização no continente americano e as conexões produzidas por tal prática através do espaço atlântico. Tais perspectivas são perpassadas por uma problematização do Estado como o horizonte das análises históricas, trazendo a necessidade de deslocar o foco analítico para a produção de diferentes espacialidades. O comércio de pessoas escravizadas foi um importante eixo de articulação entre diferentes formas espaciais e serve como ponto privilegiado para se analisar as conexões entre processos aparentemente independentes entre si que aconteceram nas costas atlânticas da América, da África e da Europa. Este artigo busca traçar tais conexões, avaliando como a articulação de diferentes formas de espacialidade através do Atlântico, mediada pelo comércio de pessoas escravizadas, orienta a historiografia da política internacional em direções diferentes das tradicionais narrativas eurocentradas. Com este texto, buscamos inserir o debate sobre escravização no cerne da disciplina de Relações Internacionais (RI).

Tal argumento se desenvolve ao longo do artigo em três passos fundamentais. Primeiramente, oferecemos uma revisão crítica da narrativa historiográfica oferecida pela Escola Inglesa. Tradição de pensamento importante no desenvolvimento de RI no

Monções: Revista de Relações Internacionais da UFGD, Dourados, v.8. n.15, jan./jun. 425

Disponível em: http://ojs.ufgd.edu.br/index.php/moncoes 
Brasil e tradicionalmente referenciada pelo destaque oferecido ao campo de História das Relações Internacionais (HRI), os pensamentos teórico e analítico da Escola Inglesa são eloquentemente silentes sobre as dinâmicas do escravismo atlântico.

O segundo passo consiste em avaliar a historiografia recente sobre o tráfico transatlântico de pessoas escravizadas, a fim de argumentar como o escravismo atlântico contempla os elementos identificados por Bull (2002) como característicos de uma instituição internacional. A partir dessa identificação, propõe-se a interpretação deste fenômeno como um aspecto fundamental da sociedade internacional em formação durante o século XIX. Este debate se dará a partir das discussões sobre a "segunda escravidão" encontradas principalmente na obra de Dale Tomich (2004). Tomando o oceano como um espaço de conexão - e não como separação -, trata-se de entender os espaços marginais (tanto do oceano em si, quanto da sociedade internacional em formação) como partes constitutivas da história. Assim, pretende-se trazer as dinâmicas sociais na América e na África como componentes centrais da sociedade internacional, figurando ao lado dos processos intra-europeus tradicionalmente privilegiados pela Escola Inglesa (BULL e WATSON, 1984; BULL, 2002; KEENE, 2002).

Por fim, trata-se de identificar os possíveis ganhos teóricos produzidos pela inserção do escravismo atlântico no cerne do arcabouço da Escola Inglesa. É importante explicar aquilo que se entende por escravismo atlântico, conceito utilizado para dar conta de principalmente dois fenômenos: o transporte, para a América, das pessoas sequestradas na África e o seu emprego na produção de mercadorias e espaços no continente americano. Ambas dinâmicas são constitutivas do Atlântico, seja nos fluxos que põem em contato os espaços, seja por meio do trabalho que transforma o espaço natural e constrói os espaços sociais. Reconhecendo que a transformação dos espaços teve particularidades em cada região da América em que a mão de obra escravizada foi utilizada, observa-se que o sentido econômico do emprego dessas pessoas em trabalhos forçados foi central no desenvolvimento e na transformação do capitalismo e, para fazer sentido dessa transformação, é importante observar 0 processo nas suas interseções e no seu desenvolvimento histórico, menos pelos constrangimentos geográficos imediatos da sua ocorrência. 
Essa opção por observar o fenômeno pelos contatos que ele propicia não ignora o fato de que se escreve a partir do espaço brasileiro e dos constrangimentos que as peculiaridades desse regime no Brasil impingiram na sociedade brasileira e no espaço - silenciado - que o país ocupa na narrativa sobre a constituição da sociedade internacional. Não se trata, portanto, de nacionalismo metodológico, mas do reconhecimento de que, ao passo que a bibliografia que trata da escravização nas Américas reconhece a profundidade do vínculo entre os EUA e o Caribe, mesmo na literatura mais clássica sobre escravização nos EUA (DAVIS, 1988; WILLIAMS, 1944), o espaço sul-americano é olvidado como um espaço internacional interligado nessa dinâmica do Atlântico. Assim, o escravismo que aporta na costa atlântica e constitui o Brasil é percebido quase que como autônomo da dinâmica setentrional. Nesses termos, essa literatura passa ao largo da importância que a experiência brasileira teve para a configuração do Atlântico como espaço de circulação (ALENCASTRO, 2000) e para a elaboração das justificativas para a escravização africana (VAINFAS, 1986). As experiências lusitanas com a escravização são parte do processo de constituição da sociedade internacional e das dinâmicas de exploração da mão de obra nos EUA e no Caribe, de forma que se faz necessário entender o escravismo atlântico como um processo que observou transformações no seu significado e que deve ser analisado como um processo não constrangido por fronteiras nacionais.

$O$ interesse em resgatar especificamente uma bibliografia sobre escravização que trabalha com o século XIX decorre da centralidade que a história desse século tem para a bibliografia de RI, em especial para a Escola Inglesa e para a constituição das instituições que são centrais para a experiência intra-europeia do século XIX. A partir daí, questiona-se se a inserção de experiências não-europeias seria suficiente para corrigir o eurocentrismo existente na narrativa histórica da criação e expansão (ou globalização) da sociedade internacional oferecida pela Escola Inglesa (SALGADO, 2019a, 2019b). É importante destacar que a ênfase na Escola Inglesa não busca tomála representativa da disciplina como um todo. No entanto, dentre as tradições responsáveis pela formulação da concepção clássica da disciplina, ela é a que mais se preocupa em avaliar o processo de formação do arcabouço normativo-institucional da política internacional moderna. Portanto, ainda que o engajamento com a Escola 

Inglesa não possa representar a totalidade da disciplina, é representativo dos limites ontológicos, epistemológicos e histórico-políticos - de uma definição clássica de RI e seu objeto de estudo. A resposta (negativa) que o presente artigo apresenta a essa questão contribui para o alargamento do objeto de estudo de RI e para apontar a insuficiência de leituras que fiquem restritas aos cânones da disciplina como forma de avançar com os debates na área.

\section{Histórias das Relações Internacionais: narrando a disciplina}

A HRI é um campo utilizado de forma muito instrumental pelas narrativas tradicionais da disciplina. Ela é majoritariamente tomada para construir argumentos de perenidade ou de instabilidade em padrões políticos. A história em HRI é tida, portanto, como exemplo que serve para legitimar a política contemporânea apresentando eventos descontextualizados em que paralelismos históricos possam favorecer 0 argumento que se quer avançar.

Apresentar a história como um conjunto de dados e informações desconectados do seu sentido de transformação e movimento empobrece as narrativas históricas dentro da disciplina de RI. Um movimento que torna fatos históricos em eventos úteis para o debate teórico compromete a HRI como um campo de interesse e reflexão. As narrativas históricas em RI foram sintetizadas por Osiander: "De fato, História é quase sempre utilizada em RI para provocar respostas pavlovianas." (OSIANDER, 2007, p. 1).

O desenvolvimento de um pensamento de RI no qual a história é vista como parte orgânica, mais integrada às análises e ao debate anglófono que prevalece no campo, é recorrentemente identificado como sendo conduzido pela Escola Inglesa de RI. Nesse sentido, vale referenciar aquilo que Gurminder Bhambra define como História: "não é simplesmente um registro 'daquilo que aconteceu', mas um registro daquilo que nós acreditávamos que aconteceu - condicionado pelos parâmetros das comunidades nas quais tais apelos são feitos - e, como tal, incorre necessariamente em imprecisões e silêncios" (BHAMBRA, 2007, p. 10). A história, então, mais do que uma outra manifestação da teoria (VAUGHAN-WILLIAMS, 2005), é também 
perspectiva. $\mathrm{E}$, no caso de $\mathrm{Rl}$, prevalece uma perspectiva eurocêntrica ${ }^{2}$ na narração da história, mais especificamente, uma perspectiva inglesa. ${ }^{3}$

O privilégio conferido pela Escola Inglesa a análises contemporâneas emolduradas por perspectivas estruturalistas é decorrência do emprego dos conceitos de "ordem", "sistema" e "sociedade internacionais", que criam a articulação de aspectos estruturais e afinidades culturais em uma única análise (BULL, 2002). O adensamento do pensamento da Escola Inglesa, fomentado por críticas internas e externas a essa corrente que apontavam para o eurocentrismo e a teleologia das narrativas lineares desenvolvidas pelos autores afiliados a essa tradição, aconteceu justamente pela construção de narrativas paralelas à história europeia que olhavam para outras fontes e experiências que não eram europeias (WEAVER, 2002; Linlater e Suganami, 2006). Edward Keene e sua narrativa do contato de europeus com outros povos (Keene, 2002), Reus-Smit e sua proposta de constituição e transformação de instituições ocidentais tais como soberania e direitos políticos (REUS-SMIT, 1999, 2011), da mesma forma que outros trabalhos sobre as transformações na política internacional (COX, DUNNE e BOOTH, 2001), têm em comum a perspectiva de construção relacional desse processo, com o reconhecimento da agência de atores não ocidentais na construção da sociedade internacional contemporânea (BUZAN e LITTLE, 2010).

Neste artigo, damos atenção especial ao que Ole Weaver (1998) chamou de quarta geração da Escola Inglesa, uma literatura mais engajada com uma releitura crítica da própria tradição e disposta a incorporar outros debates. Dessa geração, atentamos a dois livros em particular. O primeiro deles - e também o mais recente - é o

\footnotetext{
${ }^{2}$ Bhambra define eurocentrismo como: "a crença, implícita ou não, de que o significado histórico dos eventos desenvolveu-se endogenamente dentro da esfera cultural-geográfica da Europa. Ao contestar o eurocentrismo, eu contesto o 'fato' da 'especialidade da Europa' tanto em termos da sua cultura e dos seus eventos, o 'fato' do desenvolvimento autônomo dos eventos, conceitos e paradigmas, e, por fim, o 'fato' da Europa ser ela mesmo uma entidade definida e coerente que nos é imposta." (Bhambra, 2007, p. 5).

${ }^{3}$ Entendemos por narrativa histórica o esforço de construir sentido da sucessão de eventos articulados por relações de causalidade. Nessa chave, obras como Kissinger (1997) e Osiander (2007) são exemplares no campo e atingem um objetivo que não era manifesto em Waltz (1986, p. 98-99) que trata a história exclusivamente como exemplo de fatos que colaboram na construção de um argumento. Por "perspectiva" entendemos a lógica semântica que orienta a construção da narrativa: os espaços e atores privilegiados na construção das narrativas históricas. Assim Bhambra (2007) e Bull e Watson (1984) representam perspectivas diferentes, por isso suas narrativas são diferentes dado que as causalidades e o contato entre um e outro evento não é orientado pela mesma lógica em narrativas que têm perspectivas diferentes.
} 
volume editado em 2017 por Tim Dunne e Christian Reus-Smit, que propõe uma atualização ao livro de Hedley Bull e Adam Watson de 1984, The Expansion of International Society. O livro de Dunne e Reus-Smit (2017b), The Globalization of International Society aponta para uma visão da sociedade internacional que não se forma na Europa para depois se expandir, mas que se forma à medida que se globaliza, atualizando o sentido dado à "expansão". Portanto, Dunne e Reus-Smit argumentam:

As últimas três décadas foram duras com o livro [The Expansion of International Society]. Muitos dos seus elementos conceituais, suas orientações analíticas, métodos e suposições históricas, e suas perspectivas normativas foram questionados por literaturas mais recentes em RI, teoria política, história, direito e sociologia. (Dunne e Reus-Smit, 2017a, p. 4)

Em seguida, eles completam: "Apesar destes desafios, a questão central que move The Expansion mantém sua importância crítica: como a sociedade internacional global de hoje se desenvolveu?" (DUNNE E REUS-SMIT, 2017a, p. 4). Nossa questão neste artigo se relaciona com esse esforço para criticar a narrativa histórica da Escola Inglesa através das tensões apresentadas nos limites dessa atualização proposta por Dunne e Reus-Smit. Neste sentido, argumentamos que a "globalização" no título do livro ofusca a origem da sociedade internacional que, no livro de 1984, se expande. Ao fazê-lo, a narrativa atualizada continua não incorporando certos elementos ocultados pela narrativa original de Bull e Watson, aprofundando a perspectiva inglesa, eurocêntrica, da Escola Inglesa. ${ }^{4}$

Esta questão leva ao segundo livro com o qual lidamos aqui. Trata-se de Beyond Anarchical Society, de Edward Keene (2002), no qual ele aponta para a existência de algo além da sociedade internacional descrita por Bull na obra de 1977. Enquanto Bull fala sobre a coexistência na sociedade internacional, Keene se interessa pelo que há além dos limites dessa sociedade, buscando entender a ordem internacional pela perspectiva do sistema internacional. A obra de Keene se debruça, portanto, na ideia de

\footnotetext{
${ }^{4}$ Pedro Salgado (2019b) apresenta a maneira por meio da qual a construção da independência do Brasil é aspecto que foge da concepção eurocêntrica de construção de Estados desenvolvida pela Escola Inglesa. Salgado argumenta que as disputas envolvidas na constituição da independência brasileira são de outra natureza que aquelas que pautaram a soberania dos países europeus. (Salgado, 2019b, p. 6).
} 
padrões de civilização que estabelecem hierarquias. Ao fazê-lo, Keene recupera um debate sobre hierarquias nas RI. Um esforço que culmina com a produção de uma edição especial da Millennium sobre o tema em $2014^{5}$.

Considerando essas obras, nossa proposta é resgatar a ideia de "instituições", desenvolvida por Bull em 1977, que tem um papel central para esse debate sobre hierarquia. Esse esforço é uma tentativa de interpretar o escravismo atlântico como uma das instituições fundamentais da sociedade internacional. Para Bull, as instituições são:

(...) um conjunto de hábitos e práticas orientados para atingir objetivos comuns. Essas instituições não retiram do Estado seu papel principal de implementar as funções políticas da sociedade internacional, ou de substituir no sistema internacional a inexistente autoridade central. Elas manifestam o elemento de colaboração entre os estados no desempenho da sua função política, e constituem ao mesmo tempo um meio para sustentar tal colaboração. (Bull, 2002, p. 88-89)

Antes de retomarmos a historiografia da escravização no Atlântico para estabelecer sua centralidade na concepção das relações internacionais modernas, cabe indagar qual o papel que as obras mencionadas acima the prescrevem. Ao fazê-lo, percebemos uma posição curiosa: ao passo que o abolicionismo e o antirracismo são louvados como elementos cruciais da sociedade internacional (e de sua expansão) (Keene, 2007), a expansão colonial e a escravização, como um de seus elementos constituintes, são pouco mencionadas.

Se, na concepção original de Bull, a expansão colonial desde o início do século XVI é suficiente para incluir o espaço atlântico no sistema internacional, a expansão da sociedade internacional só se dá com a adesão imposta e violenta dos povos e sociedades às normas e aos valores cultivados na tradição europeia (BULL E WATSON, 1984). O próprio Reus-Smit (2011) descreve a expansão da sociedade internacional através de ondas de emancipação, nas quais as concepções de direitos individuais são ampliadas. Dentre estas, incluem-se a proibição da escravização de

\footnotetext{
${ }^{5}$ Dentre outros, constam desta edição contribuições de Tanja E. Alberts (2014), Carsten-Andreas Schulz (2014) e Dimitrios Stroikos (2014), além do próprio Edward Keene (2014).
} 
nativos no Império Espanhol, as transformações do século XIX (compreendendo tanto as independências na América quanto o movimento abolicionista) e a descolonização pós-1945. Tal concepção da expansão coaduna com a tese original da Escola Inglesa, seguindo a ideia de um "padrão civilizatório" como pré-requisito para a adesão à sociedade, que desde sua concepção na obra de Gong (1984) já inclui o respeito a um rol de direitos fundamentais que afasta a possibilidade de se aceitar práticas escravocratas ou racistas como "civilizadas". Nos termos de Gong, "[a]o menos em teoria, o padrão civilizatório não vê cor" (GONG, 1984, p. 53). Vincent (1984), da mesma forma, lista a igualdade racial como uma das virtudes centrais à sociedade internacional, enquanto Bull alerta que o movimento antirracista pode justamente ser uma das causas de "revolta contra o ocidente" que ameaçam a ordem internacional, uma vez que a ordem ocidental e a sociedade internacional de origem europeia se associam à supremacia branca sobre as demais etnias (BULL, 1984, p. 220-221).

Ora, se a abolição e o antirracismo são tão amplamente citados como virtudes trazidas pela expansão da sociedade internacional e dos valores e costumes europeus, é essencial assumir a existência prévia de uma prática de escravização que não pode ser entendida senão como parte da expansão colonial europeia pelo espaço atlântico. Dado esse cenário em que o abolicionismo é louvado como resultado da expansão europeia enquanto a escravização em si é convenientemente ignorada, o argumento apresentado aqui, de que a segunda escravidão deve ser tratada como aspecto central das relações internacionais modernas, equivale a constatar a nudez do rei. Ou ainda, se seguirmos as mais recentes inovações teóricas e historiográficas na narrativa da Escola Inglesa (DUNNE E REUS-SMIT, 2017; KEENE, 2005; CLARK, 2005) e rejeitarmos a existência de uma separação rígida entre os momentos de "sistema" e "sociedade" internacionais, precisamos considerar que toda a expansão colonial europeia (incluindo toda a violência da ocupação territorial e da escravização de populações inteiras) é parte do processo de formação da sociedade internacional e de 
suas normas (EPSTEIN, 2017). Assim, não se faz possível separar a escravização e 0 tráfico transatlântico de escravizados das origens da política internacional. ${ }^{6}$

Como veremos na próxima seção, a escravização foi um conjunto de práticas que teve um significado próprio no século XIX que não retirou dos Estados o papel de implementar funções que hierarquizaram o espaço internacional conferindo precedência a Estados europeus sobre os outros espaços do mundo. A escravização se encaixa, pois, na definição de instituição como proposto por Bull ${ }^{7}$, mas ocupa um papel silenciado na disciplina, como se representasse a instituição que não se consegue justificar.

\section{Escravizando Pessoas e Construindo Espaços}

A escravização é um tópico ainda a ser incorporado no campo de $\mathrm{HRI}$. Pesquisas recentes no campo da Economia Política Internacional trazem um debate em torno do conceito de "precariedade" (STANDING, 2011; NELSON e ROSSITER, 2008), e autores como Kevin Bales (1999) contribuem com trabalhos sobre a escravização contemporânea em Rl. O tráfico de pessoas escravizadas no Atlântico ainda não é, contudo, nos termos de Bhambra (2007, p. 10), "um registro 'daquilo que aconteceu"” na disciplina.

Repensar o cânone de RI através de uma narrativa histórica que confira ao escravismo atlântico proeminência na disciplina não é tarefa simples. Neste artigo, como já dito, debruça-se em particular sobre o fenômeno da escravização durante o

\footnotetext{
${ }^{6}$ Tal entendimento se aproxima dos argumentos apresentados por Keene (2005) e Schulz (2014) para o estabelecimento de hierarquias (e não da propalada anarquia) como uma instituição central da sociedade internacional, e da interpretação de que tal hierarquia se dá de acordo com a colonização e com a reinterpretação do "padrão civilizatório" como uma estratificação da sociedade internacional, e não como sua barreira de entrada. Nosso intuito neste artigo vai além desses argumentos, recuperando especificamente a importância da escravização para a construção de tais hierarquias coloniais e, no limite, questionando a eficácia analítica do arcabouço fornecido pela Escola Inglesa para se tratar a política internacional através do resultado produzido pelas diferentes experiências de tal violência colonial através do Atlântico.

${ }^{7}$ Bull (2002) trata originalmente de cinco instituições: equilíbrio de poder, direito internacional, diplomacia, guerra e grandes potências.
} 
século XIX, por se tratar de um período fundamental para as narrativas de desenvolvimento institucional da política internacional (JOLL, 1990; BULL e WATSON, 1984). Ao mesmo tempo, a historiografia recente aponta para as particularidades assumidas pelo escravismo durante o século XIX que justificam a criação do conceito de "segunda escravidão" (TOMICH, 2004).

A peculiaridade da escravização durante o século XIX é consequência do período histórico no qual se insere, não guardando relação com transformações nos processos de sequestro e venda de pessoas. Nesse sentido, a diferença entre a escravidão colonial (ou a "primeira escravidão") e a segunda escravidão diz respeito ao aprofundamento do liberalismo nas práticas comerciais de pessoas escravizadas e ao sensível aumento da quantidade de pessoas transportadas forçosamente pelo Atlântico (Tomich, 2004). Ao focar a análise nos diferentes espaços conectados por esse comércio, a pesquisa deixa de se orientar por Estados, ou por atores políticos domésticos. Ao contrário, privilegiam-se os espaços de trânsito que possibilitam 0 contato e assim se contribui para a história do Atlântico (SHILLIAM, 2009, 2013; LINEBAUGH E REDIKER, 2013; GILROY, 2012).

O uso de proposições históricas para justificar abordagens teóricas é um movimento recorrente na disciplina de RI (OSIANDER, 2007; VAUGHAN-WILLIAMS, 2005). Mas, sendo as teorias estadocêntricas, não se construirá uma narrativa histórica descolada de nacionalismo metodológico. Assim que processos complexos e articulados em muitos espaços, como a escravização que conecta Brasil, Costa da Mina, Cuba, Congo, Cabo Verde, França, Portugal, Estados Unidos, Haiti, Espanha, Angola, Países Baixos e Inglaterra, desde o início do período colonial até o final do século XIX, são artificialmente simplificados em fenômenos nacionais. É mais uma dentre as múltiplas violências que relatam.

É representativa dessa lógica a perspectiva que nacionaliza o escravismo brasileiro a despeito dos eventos que compõem a narrativa sobre a inserção do Brasil nas dinâmicas do tráfico de escravizados a partir do século XVI se darem em formas espaciais dificilmente compreendidas nos moldes do estado nacional. Padre Antônio Vieira enxergava que essa atividade colocava o espaço brasileiro como vanguarda da expansão do cristianismo como consequência do seu papel na expansão da fé cristã de 
populações trazidas da África (VAINFAS, 1986). O fato de o desenvolvimento econômico português, inglês ou holandês estar vinculado à centralidade assumida pelo Brasil na expansão da fé cristã reflete como os processos de modernização europeus não podem ser analiticamente reduzidos a espaços nacionais específicos, a práticas comerciais ou à adoção de normas culturais em comum. A perspectiva de David Davis está mais conforme à significação do escravagismo atlântico:

Sugerimos que a escravidão dos negros, produto de incontáveis decisões auto-interessadas de comerciantes e monarcas na Europa e na África, era parte intrínseca do desenvolvimento americano desde as primeiras descobertas [sic]. A evolução da escravidão enquanto instituição foi concomitante com a criação da ideia de América como um recomeço, uma terra de promessas onde esperanças e aspirações se realizavam. (Davis, 1988, p.24)

Decisões na Europa e na África, desenvolvimento e promessas na América: uma complexa teia de causalidades, codeterminações e influências múltiplas, que precisam ser estudadas em sua potencialidade de forma conjunta, e não segmentadas por fronteiras nacionais e distâncias físicas. Ao focar nossa narrativa histórica no processo de escravização atlântica, estamos propondo uma história vinculada a pessoas, e não aos espaços políticos - colônias, impérios, países - constituídos por elas. ${ }^{8}$ Esta é a proposta de uma história que recusa nacionalismos metodológicos os quais aceitam os espaços estatais como arenas primordiais (e trans-históricas) da atividade política. Ao contrário, ao focarmos em pessoas (e nas relações que elas estabelecem entre si e com o mundo), reconhecemos as agências que constituem formas espaciais distintas. O Atlântico, portanto, deixa de ser um "vazio político" entre os espaços nas suas margens, podendo ser entendido como uma forma espacial própria consolidada pelas práticas que justificam (ou demandam) suas várias travessias.

A ideia de "segunda escravidão" proposta por Tomich (2004) atende a essa sofisticação da narrativa ao apresentar o Oceano Atlântico como um espaço moldado

\footnotetext{
${ }^{8}$ Inspiram a construção desse texto trabalhos como o de Paul Gilroy (2012), O Atlântico Negro, e de Alberto da Costa e Silva (2011), Um Rio Chamado Atlântico, além de O Trato dos Viventes, de Luiz Felipe de Alencastro (2000), que mostram como os contatos entre os continentes é constitutivo da vida das pessoas.
} 
pelos interesses religiosos, econômicos e políticos em torno do transporte de pessoas escravizadas. Isso só é possível ao se considerar que tais interesses são projetados sobre (e efetivamente constituem) outras formas espaciais para além da territorialidade fixa dos Estados nacionais. Em outras palavras, o Estado deixa de ser o espaço político preponderante, se tornando apenas uma (dentre diversas possíveis) formas de espacialização da política. O papel do tráfico de escravizados na constituição - ou desenvolvimento - do capitalismo é essencial para Tomich e para os debates que figuram em sua obra. "A escravidão nas Américas foi o produto histórico da expansão da economia-mundo europeia" (TOMICH, 2004, p. 3): assim ele dá início ao primeiro capítulo do livro. A característica do debate sobre a segunda escravidão é uma contribuição do campo para a capacidade de, através da análise de um processo específico ao Atlântico, articular dinâmicas internacionais que ultrapassam o Estado.

É importante esclarecer esse conceito de segunda escravidão: trata-se do uso de mão-de-obra escravizada no século XIX, um período marcado pela emergência do liberalismo na economia e de seu fortalecimento no âmbito político. Liberalismo manifesto inclusive através da Revolução Haitiana. Portanto, a segunda escravidão não difere do modelo colonial pelos métodos coercitivos empregados na captura ou no aprisionamento de pessoas, ou pela relevância destas para o dinamismo econômico do período. A diferença diz respeito ao significado da manutenção deste modelo de trabalho.

É importante ressaltar que desde que o modelo escravagista foi aplicado nas Américas, já guardava diferenças importantes em relação à escravização antiga. Pessoas africanas não foram trazidas para o seio dessa estrutura como consequência da derrota em algum conflito específico: desde o início, o propósito era sua escravização (BLACKBURN, 1997, p. 12). Portanto, o sistema, cuja legitimação se deu com o projeto de expansão da Cristandade, não sofreu de início a oposição de formas de trabalho livre. Ao contrário, no polo oposto encontravam-se os ideais de civilização cultivados na Europa e a tradição Cristã. A leitura histórica que contrapõe o trabalho livre à escravização desde o começo das práticas coloniais no Atlântico é fruto de um anacronismo, uma vez que atribui caráter trans-histórico a uma dualidade que pertence a um contexto particular, o contexto a partir da Revolução Industrial em que o trabalho 

livre passou a ser discutido como possibilidade real. Como o próprio Blackburn afirma, a ideia de que a escravidão representa o atraso é uma leitura equivocada, pois o escravismo atlântico era um projeto moderno (BLACKBURN, 1997, p. 4) que foi combatido pela ideologia do Antigo Regime europeu (LOSURDO, 2014, p. 34).

Eric Williams (1944) representa a corrente historiográfica que ajudou a construir esse imaginário de antagonismo entre a lógica capitalista e o uso de trabalho escravizado. Em seu livro, Williams (1944, p. 5-6) argumenta como Adam Smith, em 1776, critica essa exploração de trabalho por meio da violência, mas principalmente pela sua não-racionalidade produtiva, fruto de paixões e interesses de outra natureza que não econômica. De alguma forma, Smith está criando essa distinção entre racionalidade econômica e política, na qual lógicas distintas podem operar e competir pela prevalência no mundo social. Todavia, assumir de uma só vez que a manutenção do trabalho escravizado é antagônica ao desenvolvimento capitalista pelo pouco incentivo à produção da força de trabalho leva à armadilha de afirmar que os dois modelos são mutuamente excludentes, que não poderiam coexistir temporalmente. Tomich (2004) argumenta o contrário: para ele, a manutenção da escravização nas Américas representa uma condição de possibilidade fundamental para 0 desenvolvimento industrial europeu, uma vez que permitiu a absorção de mercadorias baratas pelas manufaturas nascentes. "Longe de ser uma instituição moribunda durante o século XIX, a escravidão demonstrou sua adaptabilidade e vitalidade" (TOMICH, 2004, p. 69).

Outro debate no qual Tomich se insere diz respeito à forma como ele apresenta a contradição essencial do sistema escravagista não como a tensão gerada pelos debates sobre a ideia de escravidão, mas pelos papéis atribuídos ao centro e à periferia no sistema global de divisão do trabalho e distribuição de bens e riquezas. Esse debate surge entre as tradições da Nova História Econômica, do Marxismo Histórico e da Teoria dos Sistemas-Mundo pelas formas como tratam a escravização no século XIX, e se reproduz na historiografia brasileira ${ }^{9}$, contrapondo principalmente as perspectivas

\footnotetext{
9 No debate historiográfico brasileiro sobre segunda escravidão, cabe destacar as correntes neogramscianas e mundo-sistêmicas que ficam evidentes no livro organizado por Rafael Marquese e Ricardo Salles (2016). Nesse livro, o texto dos organizadores se propõe a fazer uma revisão historiográfica sobre
} 
Neogramscianas e dos Sistemas-Mundo, conforme o próprio Tomich (2004, p. 37-46) antecipara no dualismo entre o debate sobre a transição para o capitalismo e a teoria mundo-sistêmica ${ }^{10}$.

A narrativa de Tomich (2004), assim como a história da escravização no Atlântico de uma forma geral, se contrapõe à percepção do presentismo que marca a subárea de $\mathrm{HRI}$. A forma por meio da qual a hierarquização dos espaços é construída ao longo do tempo nas margens do Atlântico é de tal ordem que eventos ocorridos no século XVI seriam impensáveis no século XIX dada a supressão de autonomia do espaço colonial. A narrativa de Luiz Felipe de Alencastro (2000, p. 218-231) sobre a expulsão dos holandeses das colônias portuguesas na África (no século XVII) como um esforço do Rio de Janeiro que se contrapõe ao esforço paulista da Bandeira dos Limites argumenta justamente nesse sentido. De acordo com Alencastro, as tentativas concomitantes de, por um lado, reestabelecer o domínio português sobre Angola e, por outro, da exploração do interior brasileiro em busca de nativos a serem escravizados formam uma imagem do Brasil como um espaço político dinâmico, capaz de empreender simultaneamente duas tentativas de expansão geopolítica motivadas por ambições escravagistas. Ao fim, e ainda de acordo com Alencastro, o sucesso nas guerras contra os holandeses e a incapacidade dos bandeirantes de encontrar contingentes populacionais grandes o suficiente para a demanda de trabalho nas fazendas consolidaram o comércio de africanos escravizados como o principal eixo de integração do Atlântico.

Estas articulações político-econômicas, bem como a ampla gama de consequências que elas produziram, revelam que o ponto de partida de tal análise do escravismo atlântico pode ser situado em uma narrativa histórica de longue durée. A importância da escola dos Annales na historiografia é crucial para a compreensão do

o tema é abordado. Apesar do presente trabalho se construir com base nessa historiografia (Tomich, 2004; Marquese e Salles, 2016; Blackburn, 1997), o mapeamento dessa literatura através de uma revisão bibliográfica mais aprofundada transformaria significativamente o escopo do artigo.

10 Tais debates se apresentam com clareza na organização de eventos e grupos de estudos que permitem a proliferação de ideias e discussões sobre o tema, como o simpósio temático no encontro da ANPUH no estado do Rio de Janeiro chamado "O Vale do Paraíba, Segunda Escravidão, e Civilização Imperial", o Grupo de Pesquisa em Escravidão no Século XIX (GREXIX) na UNIRIO, os debates do Núcleo de História Mundial e Comparada da UFF e o Laboratório de Estudos sobre o Brasil e o SistemaMundo (Lab-Mundi) da USP. 
desenvolvimento da literatura da qual partimos aqui ${ }^{11}$. Cabe uma menção especial a Immanuel Wallerstein (2004) que, ao seguir as análises de Ferdinand Braudel (1983, 2001, 2009) do mundo mediterrâneo através de suas conexões, propõe uma percepção do desenvolvimento das relações internacionais que não se limita à economia ou à política, mas que considera também a contribuição destas para o desenvolvimento de uma geocultura ${ }^{12}$. Marquese e Salles (2016), ao discorrerem sobre escravização, demonstram a importância desta literatura:

Mesmo a escravidão doméstica, praticada por indivíduos não raro libertos ou descendentes de libertos, possuidores de um ou dois cativos, amplamente disseminada espacial e socialmente no Brasil dos oitocentos, só foi possível e se desenvolveu por conta do significado simbólico, social e econômico que a escravidão mercantil conferia à posse de cativos. $\mathrm{O}$ tráfico internacional de escravos foi o grande mecanismo que permitiu essa difusão da escravidão brasileira. A plantation escravista do século XIX não foi um enclave que se sobrepôs a um tecido social e escravista disperso herdado do século XVIII: foi sua espinha dorsal. (Marquese e Salles, 2016, p. 130)

O desenvolvimento desta ampla narrativa do escravismo atlântico é visto por esses autores como uma resposta aos limites de estudos micro-históricos da escravização que predominaram até então. Não se trata de diminuir a contribuição dessa tradição, que enriqueceu o entendimento da escravização, de seus processos e violências características, para além de narrativas sistêmicas abstratas (MARQUESE E SALLES, 2016). Para eles, com o conceito da segunda escravidão, "[t]rata-se, neste momento, de buscar análises que se voltem para conexões, os nexos, e as contradições que compõem esses objetos enquanto totalidades estruturadas, ou parte delas, produzidas pelas ações humanas ao mesmo tempo que as condicionam" (MARQUESE E SALLES, 2016, p. 132). É o fato de a história ser contada através de suas conexões e contradições que dá ao sistema escravista atlântico um dinamismo político.

Debruçar-se de tal forma sobre a história da escravização é desafiador.

\footnotetext{
${ }^{11}$ Para um relato mais detalhado da importância da historiografia dos Annales, ver Burke (2010).

12 Para uma discussão detalhada sobre o conceito de geocultura, ver Wallerstein (2004).
} 
Demanda um esforço no sentido de diminuir a importância de fronteiras e percepções estadocêntricas da narrativa histórica, sem descartar a agência política de figuras ligadas ao Estado. O desafio vem justamente da tradição de se considerar o Estado como locus da agência política dos indivíduos. Junto ao desafio apresentado à interpretação liberal do mundo pela importância da escravização em espaços econômicos periféricos ao capitalismo, somos deixados com um segundo problema: como é possível que uma narrativa política que reafirma a importância do espaço político - por excelência, o Estado - se molde através de múltiplas conexões que se dão para além do Estado? Em outras palavras, como é possível que o comércio de pessoas escravizadas no Atlântico, em uma dinâmica que precede a consolidação de Estados nas duas margens do oceano, tenha ajudado a criar as múltiplas hierarquias que caracterizam não apenas o sistema de Estados no século XIX, mas também suas sociedades nacionais?

Reconhecer a história como uma narrativa política, envolta em dinâmicas e contradições próprias, é um primeiro passo rumo ao entendimento de que podem existir outros espaços políticos além do Estado. Talvez seja possível que se forje um "internacional" específico, algum espaço para além de qualquer tipo de "nacional", ou seja, além de qualquer fronteira. Talvez esses espaços possam ser os mares e oceanos. Então, tais espaços seriam ressignificados como espaços de contato, e não de diferenciação, permitindo uma imagem de um "Rio Atlântico", no lugar de um Oceano Atlântico (SILVA, 2003).

\section{Historiografia na Teoria de RI: O Conto de Dois Oceanos}

Os nomes dos livros de Luiz Felipe de Alencastro, O Trato dos Viventes: formação do Brasil no Atlântico Sul, e de Alberto da Costa e Silva, Um Rio Chamado Atlântico: a África no Brasil e o Brasil na África, apontam que estes dois historiadores consideram o Atlântico como um espaço de trocas particularmente relevante para a formação histórica do Brasil. Contudo, a disciplina de Rl, com raras exceções (BARTELSON, 1995; CONNERY, 2001; THOMSON, 1994; YAMATO, 2011, 2019, 2020 
GUSTAVO A. G. BEZERRA \& PEDRO SALGADO \& ROBERTO V. YAMATO (no prelo); MATOS, 2019) ${ }^{13}$, ao se debruçar sobre a origem da política internacional moderna, pouco diz sobre tal espaço, tratando-o como politicamente vazio ou insignificante $^{14}$. Movendo o foco da análise para um dos grandes silêncios da disciplina - o comércio de pessoas escravizadas no Atlântico -, enxergamos o Atlântico como um espaço político importante, contribuindo para a disciplina ao apontar espaços de interação social e política para além dos que são tradicionalmente privilegiados pela literatura.

Essa literatura revisionista sobre a escravização no século XIX demonstra que é possível desenvolver uma narrativa histórica do comércio de pessoas que considera 0 Atlântico como um espaço político. A questão com a qual nos deparamos ao fazê-lo (e

\footnotetext{
13 Jens Bartelson, por exemplo, ao comentar a relação entre o que chamou de "protosoberania" e a "invenção de foras", destaca a relevância dos mares, como uma forma de limite, à emergência de um pensamento político (internacional) moderno: "Os mares - à exceção do Mediterrâneo - eram ainda amplamente inexplorados e pouco mapeados, e figuravam, metaforicamente como barreiras ao conhecimento político e autoridade. Autoridade não se estendia mar a dentro e, para além do seu escopo, existia um "fora" desconhecido e inavegável, um elemento não territorial não suscetível ao domínio humano." (Bartelson, 1995, p. 105). De outro modo, Christopher L. Connery observa que o "oceano" tem sido concebido como um "fora constitutivo" da concepção telúrica de espaço e território no âmbito do imaginário oceânico europeu que se tornou hegemônico desde o século XIX. Nestes termos, Connery destaca que o oceano se tornou "praticamente inseparável da história do conceito de internacional, tal como nós o conhecemos" (Connery, 2001, p. 177). Em seu estudo de sociologia histórica internacional, Janice E. Thomson, por sua vez, argumenta que a consolidação do Estado soberano moderno e, com ele, a do sistema de Estados soberanos envolveu a eliminação e/ou o controle de diferentes formas de violência individual não-estatal extraterritorial (pirataria, privateering, filibustering) por parte do Estado soberano e do sistema de Estados. Assim, a formação histórico-sociológica de uma ordem internacional global se deu apenas com a efetiva domesticação dos "altos-mares": "[a]penas com a universalização de metanormas contra a violência individual em alto-mar é que as áreas do Globo não sujeitas à soberania foram convertidas de um estado de natureza para um domínio de relação ordeira entre os Estados." (Thomson, 1994, p. 140). Inspirado nos trabalhos de R. B. J. Walker e Jacques Derrida, Roberto Vilchez Yamato desenvolve uma releitura do trabalho de Carl Schmitt e de seu pensamento político - internacional -, e, com ele, de RI, em que sugere a (des)articulação de certas práticas de categorização e a legitimação de formas excepcionais de violência por meio da (des)construção de "foras" e "forasteiros constitutivos", tais como o "mar", o "pirata" e o "inimigo da humanidade" (Yamato, 2011, 2019, 2020 (no prelo)). Nesse sentido, para uma releitura sobre o "sacrifício do mar" no contexto de formação do pensamento político moderno, sobretudo no que se refere ao trabalho de Schmitt, ver a tese de doutorado de Francisco Matos (2019).

${ }^{14} \mathrm{O}$ privilégio analítico conferido a espaços terrestres tem origem nos clássicos da geopolítica (Mackinder, 1904) e é articulado em detalhes por Carl Schmitt (2003). Segundo este, tradicionalmente tem-se uma divisão geopolítica entre a terra como espaço ordenado, dividido por linhas de fronteira e propriedade, enquanto, mesmo no século XIX, "[0] mar permanecia alheio a ordens estatais específicas: não era Estado, nem território colonial, nem espaço ocupável. Estava livre de qualquer tipo de soberania espacial do Estado. A terra firme era dividida por fronteiras lineares bem definidas. $O$ mar não tinha fronteiras senão a costa. Era a única superfície territorial livre de Estados e aberta ao comércio, pesca, e disputas militares, independente da proximidade ou de fronteiras geográficas." (Schmitt, 2003, p. 172). Nesse sentido, para uma leitura (mitológica) da relação entre terra e mar, e os elementos (terra, mar, ar e fogo) em geral, ver também seu Land and Sea (Schmitt, 2015).
} 
que tentamos responder nesta seção) é: o que produziu tamanho silêncio sobre o tema na literatura clássica de RI? A primeira possibilidade diz respeito às diversas influências liberais sobre a disciplina. Por exemplo, como o liberalismo político manifesto nas propostas de Wilson ao final da Primeira Guerra é posteriormente desenvolvido a partir de releituras de filósofos liberais (Locke, Mill, Kant, et al.) para analisar a política internacional. Ao fazê-lo, naturalizam-se no discurso liberal (e naquele que posteriormente convencionou-se chamar de neoliberal) as violências presentes na formação dos Estados e da ordem internacional contemporânea, assim como fazem tais filósofos do iluminismo ${ }^{15}$. Por exemplo, a justificativa com base na obra de Locke (mas ainda comum no século XX) de que povos na "infância do progresso" precisam da tutela de civilizações avançadas para que alcancem o estágio evolutivo destas últimas, o que estabelece ao mesmo tempo a ideia de povos primitivos como "irracionais" (portanto, incapazes de estabelecer laços de propriedade), e os posiciona como uma versão do passado europeu, legitimando a ocupação colonial (BHAMBRA, 2007).

Ao passo que Bhambra (2007) argumenta sobre a forma por meio da qual esse eurocentrismo constrói a legitimação para a ocupação colonial, Losurdo (2014, p. 3744) argumenta sobre a maneira por meio da qual o liberalismo político é construído em paralelo ao aprofundamento do escravismo atlântico, articulando a construção de um universalismo inclusivo liberal com a manutenção da marginalização dos sujeitos escravizados sem que isso criasse uma oposição que enfraquecesse a viabilidade política do colonialismo europeu. A tradição econômica do liberalismo, cuja origem remonta às contribuições de Adam Smith e David Ricardo entre os séculos XVIII e XIX e que não raro reaparece como neoliberalismo nessa virada para a década de 2020, é persuasiva em decorrência do arcabouço teórico no qual atores racionais são analisados à margem de considerações sobre seu contexto social e/ou geopolítico. Assim, tal abstração das condições materiais possibilita os postulados de igualdade de condições entre os indivíduos competindo livremente e as possibilidades quase

\footnotetext{
${ }^{15}$ A abordagem que tanto Jahn (2013) quanto Losurdo (2014) utilizam para analisar o Liberalismo (seja exclusivamente nas RI, como o primeiro, ou a trajetória mais universal como o segundo) é reconhecendo a forma por meio da qual essas perspectivas teóricas vinculam-se com a política que lhe é contemporânea, motivo pelo qual esses dois livros, bem como Bhambra (2007), são as fontes para desenvolver nosso entendimento sobre liberalismo.
} 

ilimitadas de transformação da vida individual. A ideia de atores em competição pela realização dos seus desejos de maneira utilitária e racional é parte crucial desse legado economicista liberal, que não é capaz de reconhecer a agência histórica de uma pessoa escravizada - por exemplo - produzindo seu apagamento histórico e legitimando a violência originária desta condição. Ademais, tal compreensão do homo economicus produz uma tensão com a percepção política do liberalismo, que caracteriza os seres humanos pela busca de suas capacidades individuais (BURCHILL, 1996; JAHN, 2013).

Esta curta digressão sobre o liberalismo e sua relevância para a origem da disciplina é um caminho para discutirmos uma perspectiva da história que se desenvolve a partir do conceito eurocêntrico e liberal do "indivíduo". Uma narrativa histórica de progresso alcançado não por meio de conflito, mas pelo desenvolvimento racional da humanidade na direção de um futuro melhor e mais avançado. ${ }^{16}$ Não se pretende aqui estabelecer uma equivalência entre o pensamento liberal em $\mathrm{Rl}$ e a Escola Inglesa, mas apontar para como os trabalhos históricos desenvolvidos sob as premissas dessa tradição incorporam pressupostos liberais em uma acepção mais ampla dessa tradição (Thakur et al., 2017). Dessa forma, a narrativa teleológica e a noção de progresso manifestas no ideário civilizacional (Keene, 2002, 2014; Linklater, 2017) representam como a Escola Inglesa é passível de ser entendida à sombra do pensamento liberal.

Isto nos leva à segunda razão pela qual a escravização não é abordada como um fenômeno fundador da política internacional moderna: o eurocentrismo latente desse "cânone". A crítica ao eurocentrismo tem sido um tema recorrente no campo de teoria crítica de RI, englobando o apagamento do papel de teóricos marginalizados no desenvolvimento acadêmico da disciplina e das contribuições de atores não-europeus nos processos históricos da política internacional (VITALIS, 2015; ANIEVAS E NISANCIOGLU, 2015; TANSEL, 2015; SHILLIAM, 2009). O termo é também usado para interrogações aos pressupostos ontológicos e históricos assumidos por autores que oferecem grandes sistematizações da política internacional (BHAMBRA, 2007; MATIN, 2013; DUZGUN, 2018).

\footnotetext{
${ }^{16}$ Para mais sobre a História do Liberalismo, ver Domenico Losurdo (2014), Liberalism: a counter-History.
} 
A Escola Inglesa, em particular, tem sido alvo frequente de tais críticas. Cabe retomar aqui a discussão sobre essa tradição para avaliar seus pressupostos históricos (sem prejuízo da discussão teórica anterior). Por um lado, a narrativa clássica de origem e expansão da sociedade internacional oferecida por Bull e Watson (1984) gera uma imagem difusionista da história global onde a Europa aparece como fonte do desenvolvimento histórico como um todo, e atores não-europeus são relegados ao papel de ameaça à ordem internacional. Tal crítica é inclusive incorporada pelas contribuições mais recentes à Escola Inglesa, que buscam inovações teóricas e narrativas alternativas que sejam capazes de afastar este eurocentrismo original (REUS-SMIT E DUNNE, 2017; WELSH, 2017; LINKLATER, 2016, 2017; SCHULZ, 2014; CLARK 2005), ainda que com graus de sucesso variados e questionáveis ${ }^{17}$. A ausência de menções ao escravismo atlântico na Escola Inglesa chama a atenção de forma particular, dado o papel central da Inglaterra no comércio colonial de escravos, e mesmo no início do período da segunda escravidão ${ }^{18}$. Tal silêncio é compreensível, dada a origem da Escola Inglesa como um incentivo governamental para pensar instrumentos analíticos para a política internacional nos anos 1950, através do British Committee on the Theory of International Politics (LINKLATER E SUGANAMI, 2006).

Tal Comitê reunia diplomatas, juristas e historiadores, visando a uma perspectiva mais ampla sobre fenômenos internacionais. O papel do direito no arcabouço teórico da Escola Inglesa merece atenção especial. Mencionado entre as instituições fundamentais de Hedley Bull (2002, p. 147), o direito internacional exerceu função importante na legitimação da segunda escravidão. As tentativas do governo britânico de proibir o tráfico de pessoas escravizadas através de tratados com o Brasil (GRAHAM, 1968) são um exemplo de instrumentos legais lidando com a escravização. Contudo, o

\footnotetext{
${ }^{17}$ Para detalhes sobre a crítica ao Eurocentrismo da Escola Inglesa, em especial a estas contribuições recentes, ver Salgado (2019a, 2019b) e Seth (2011).

${ }^{18}$ Apesar da entrada tardia na disputa colonial (em meados do século XVII), a Inglaterra rapidamente se consolida como uma das principais potências coloniais ao longo século XVIII, o que inclui ser um dos principais participantes do tráfico transatlântico de escravizados, passando inclusive a exercer 0 monopólio do tráfico nas colônias espanholas (asiento) a partir de 1713 (Blackburn, 1997, p. 269, 383, 388-390). O período da "segunda escravidão", no qual a escravização passa a ter novo significado no contexto do capitalismo mundial do século XIX (Tomich, 2004, p. 57), é resultado, entre outras coisas, do pioneirismo inglês nas técnicas de navegação e redução da mortalidade de escravizados nas viagens marítimas (Blackburn, 1997, p. 392-393).
} 
direito internacional nem sempre foi mobilizado para a promoção de igualdade, não raro sendo usado no sentido contrário (SIMPSON, 2004).

Edward Keene (2002) discute a expansão da sociedade internacional a partir da Europa para o resto do mundo, demonstrando como esse movimento se deu através da construção de hierarquias com o auxílio do direito internacional. Em si, não se trata de uma afirmação trivial, uma vez que, por muito tempo, negou-se a ideia de que a evolução da sociedade internacional tivesse um processo claramente discernível. Por exemplo, Bull (2002, p. 26-38) narra extensamente a evolução de uma "Sociedade Internacional Cristã" em uma "Sociedade Internacional Mundial". Neste sentido, Bull resume a história das relações internacionais através das mudanças surgidas no ideário político através do tempo, mas sempre tomando por referência a realidade europeia.

A construção de hierarquias, como apresentada por Keene, se deu através do uso de instrumentos legais que promoviam a diferenciação de espaços políticos. Neste movimento, Keene retoma Hugo Grotius e apresenta as maneiras pelas quais essa construção de diferenças se dava através da ideia de "civilização". Ao fazê-lo, Keene demonstra o poder constitutivo do direito que cria e mantém segregações entre espaços

O conceito de civilização cumpre dois papéis no pensamento jurídico internacional: ele definia a fronteira entre as duas formas de ordem moderna internacional e descrevia o propósito último para o qual se destinava a ordem extra-europeia. Essa visão de um mundo bifurcado estava plenamente desenvolvida já em meados do século XIX, e pode-se ver em textos do direito internacional daquele período uma distinção amplamente aceita entre a família das nações civilizadas e o mundo atrasado e não-civilizado além da Europa (ainda que tal distinção já tenha sido feita em momentos anteriores). (KEENE, 2002, p. 6-7)

A crítica de Keene, ao mesmo tempo que apresenta a construção das hierarquias e da violência que forma os Estados em espaços políticos periféricos, não é suficiente para representar o processo de dominação colonial, uma vez que ela ainda se volta para o espaço político estatal. Nas análises de Keene, a hierarquia ainda é definida em termos espaciais: países na Europa têm precedência sobre estruturas políticas além do continente. Em tal leitura, o escravismo atlântico é invisibilizado, uma 
vez que permanece atrelado ao Estado e analiticamente distinto em processos de sequestro, de venda, de transporte transoceânico de indivíduos reduzidos à sua capacidade de trabalho no destino desse tráfico. Tudo isso se dá para além do Estado, e além do alcance da disciplina de RI. Para trazer essa discussão, é essencial que ela seja capaz de transcender os debates que marcam a disciplina e que os instrumentos de análise sejam usados de maneira a questionar o conhecimento já cristalizado sobre as origens da política internacional.

A terceira proposição sobre o longo silêncio da Escola Inglesa a respeito da escravização refere-se ao estadocentrismo como pressuposto metodológico: a atribuição do Estado como o principal foco dessa corrente teórica e seu tratamento como sujeito dotado de racionalidade própria $^{19}$. Se, por um lado, a analogia que considera o Estado como um sujeito racional dotado de interesse próprio já foi amplamente criticada, dando origem ao campo de Análise de Política Externa (PINHEIRO E MILANI, 2012), a centralidade conferida ao Estado em RI é de trato mais difícil $^{20}$. A questão da escravização suscita essas duas questões, uma vez que as principais narrativas sobre ela estabelecem suas conexões com os Estados nos quais as forças de trabalho escravizadas são empregadas. Portanto, existem narrativas sobre a escravidão no Brasil (ALONSO, 2015; CARVALHO, 1998a, 1998b), separadas das que tratam do tema no Estados Unidos (JOHNSON, 2013; KARP, 2016; RANDAL E DONALD, 1961; POST, 2011). Olhar para a escravização como um sistema transatlântico de conexões é argumentar que tais narrativas apontam apenas para as consequências desse sistema, ao invés de abordar a estrutura que permitiu que tais resultados fossem produzidos nos contextos específicos. Assim, se considerarmos o comércio transatlântico de escravizados como uma instituição fundamental da sociedade internacional, podemos ser capazes de desenvolver um entendimento de RI

\footnotetext{
${ }^{19}$ Essa característica é feita clara na primeira frase do livro de Bull: "Este livro é uma investigação sobre a natureza da ordem na política mundial, especialmente na sociedade dos Estados soberanos, através da qual, na medida em que existe, essa ordem é mantida na política mundial." (BULL, 2002, p. 1)

${ }^{20} \mathrm{O}$ "estadocentrismo" da disciplina é tema antigo, e a busca por alternativas deu origem a diversas tradições teóricas nas RI, como os estudos liberais de governança global (ROSENAU, 2006a, 2006b), diferentes correntes do pensamento marxista (COX, 1981; ROSENBERG, 1994) e as teorias pósestruturalistas (Campbell, 1992, 1998; Weber, 1995). Para uma análise do potencial e dos limites da crítica ao estadocentrismo, vide Lacher (2003).
} 
como uma disciplina menos apegada ao Estado, sendo, portanto, mais reticente ao encarar fronteiras como linhas de separação.

Nossa proposta de tratar a escravização como uma instituição no século XIX é o reconhecimento de que se trata de um "conjunto de hábitos e práticas moldados à realização de objetivos comuns" (BULL, 2002, p. 88). Pelo menos comuns àqueles que dela participavam voluntariamente, claro. O aspecto excludente da instituição não é um problema per se. Instituições não precisam ser universais para afetar a todos os Estados. Os exemplos de "sistema administrativo das grandes potências" e "balanço de poder" demonstram que os papéis não são distribuídos de maneira equânime nessas instituições, sendo possível, portanto, propor essa leitura, uma vez que ao fazê-lo chegamos à noção de que "elas são uma expressão do elemento de colaboração entre Estados no correr de suas funções políticas - e ao mesmo tempo um meio de sustentar tal colaboração" (BULL, 2002, p. 71).

Se a escravização atlântica perpassa toda a sociedade internacional como uma de suas instituições fundamentais, restam-nos duas questões: quais as consequências desse fato? O que ele significa para a questão do poder na política internacional? A cada uma dessas perguntas vê-se duas possibilidades de respostas que representam aquilo que identificamos como possibilidades de agenda de pesquisa a partir desse texto.

Sobre a primeira questão, ao reconhecermos o papel constitutivo do sistema escravagista atlântico em RI, somos capazes de abraçar as críticas feitas à disciplina que denunciam seu eurocentrismo e seu racismo sistêmico (DOTY, 1998; SHILLIAM, 2013; MAYBLIN, 2013). Somos capazes de fazê-lo sem abrir mão da capacidade explicativa e dos conceitos oferecidos por teorias já estabelecidas, em parte porque essas características são constitutivas da política performada nesse sistema eivado, na origem, de desigualdades e exclusões. A possibilidade de evidenciar aquilo que está implícito pode ser o aspecto disruptivo da construção de outra narrativa histórica.

Contudo, ao nos aproximarmos de outra visão crítica da Escola Inglesa e da forma como seus conceitos ("sociedade internacional", "instituição" etc.) operam analiticamente, a resposta assume outro caráter. Afinal, o eurocentrismo que atravessa as narrativas de expansão (ou, recentemente, de globalização) da sociedade 
internacional está relacionado não apenas à leitura difusionista da política internacional, mas também ao apagamento das contribuições de atores não-europeus para 0 desenvolvimento institucional da própria Europa (BULL E WATSON, 1984; REUS-SMIT E DUNNE, 2017). Quando se trata a escravização nos termos de Bull, esses parâmetros eurocêntricos que sustentam seu arcabouço teórico e sua narrativa histórica permanecem inquestionados. Ao contrário, inclusive se confere certa legitimidade às suas pretensões de universalidade, demonstrando que esse eurocentrismo pode ser expurgado com a mera adição de novas instituições que evidenciem a violência colonial sobre a qual se baseia a sociedade de Estados ${ }^{21}$. Portanto, partindo de uma crítica anti-eurocêntrica da tradição da Escola Inglesa, é necessário rejeitar a possibilidade de se resumir a história da escravização a um mero adendo da narrativa de expansão/globalização da sociedade internacional. Para que tal história seja tratada em seus próprios termos, como demonstrado pela historiografia elencada neste artigo (Alencastro, 2000; Silva, 2008; Tomich, 2004), o arcabouço teórico da Escola Inglesa é insuficiente.

A segunda questão se aproxima da primeira, não só por comportar respostas diferentes, mas também porque, ao reconhecer que há algo a mais entre as instituições de RI, implica um questionamento da noção do espaço e do sentido do poder. O argumento apresentado aqui permite uma maior precisão ao localizar o poder na política internacional. Uma vez que desafiamos as fronteiras ao enfatizar espaços de contato entre diferentes forças sociais e geopolíticas, não podemos mais dizer que o poder se restringe aos Estados, mas se encontra em espaços definidos por suas instituições, nos quais a política se articula em múltiplas direções. Ao mesmo tempo, o conceito de poder deve levar em conta quem são os atores dotados da autoridade de formular a história e o que se considera nesta história.

Por outro lado, como a agência histórica se faz pouco presente enquanto categoria analítica no arcabouço da Escola Inglesa, a discussão sobre os rumos dados pelas instituições ao desenvolvimento da sociedade internacional tradicionalmente

${ }^{21}$ Esta mesma crítica se aplica à forma como Carsten-Andreas Schulz reinterpreta o "padrão civilizatório" de Gong, argumentando que o colonialismo seria uma instituição fundamental da sociedade internacional (Schulz, 2014). 
confere pouca ênfase a disputas de poder e conflitos para além das disputas entre grandes potências. Desta forma, atribuir o tratamento de "instituição" ao escravismo atlântico não diz respeito aos projetos (geo)políticos específicos que o tornaram possível, ou às formas de resistência adotadas por suas vítimas. Tal tratamento teórico não traz à tona as relações de poder que constituem a violência colonial originária do sistema de Estados, por esbarrar justamente nessa limitação teórica em relação ao tratamento analítico conferido à agência. As "instituições" da Escola Inglesa permitem pouco espaço para se pensar os conflitos entre estratégias formuladas por atores com interesses contraditórios e mutuamente excludentes. Portanto, pode-se argumentar que entender a política internacional a partir de suas raízes na violência colonial do escravismo atlântico requer uma reformulação mais profunda do arcabouço teórico da disciplina (SALGADO, 2019b).

\section{Conclusão}

O escravismo atlântico no século XIX representa uma agenda de pesquisa com avenidas de diálogo importantes com diversas leituras teóricas das RI. Ao centrarmos nossa crítica na Escola Inglesa, fazemo-lo não apenas pela forma como essa tradição teórica arrogou para si a incorporação da narrativa histórica no seu ethos acadêmico, mas sobretudo por se propor a construir uma interpretação universal de RI ainda que seja conhecido - e eventualmente reafirmado - seu caráter "inglês", ou seja, sua relação particular com os legados do colonialismo europeu.

Argumentamos que, ao entendermos o escravismo atlântico como uma instituição constitutiva da sociedade internacional, no sentido dado por Hedley Bull (2002), damos visibilidade à violência colonial, trazendo-a para o cerne da formação institucional da política internacional moderna e, por conseguinte, da disciplina de RI. Trata-se, contudo, de uma instituição silenciada pela disciplina, apesar de sua importância para a construção do espaço Atlântico, um pano de fundo da sociedade internacional, uma condição de possibilidade para o desenvolvimento das outras instituições apresentadas por Bull. A partir desse argumento, resta questionar se é 
válido utilizar os instrumentos teóricos oferecidos pela Escola Inglesa, que primou pelo silenciamento dessa prática, ou seja, se o instrumental ofertado por essa tradição pode servir para os propósitos críticos que se busca encorajar.

Recuperando 0 debate sobre a segunda escravidão nas literaturas historiográficas do Brasil e dos Estados Unidos, nossa intenção é apresentar os espaços que podem ser preenchidos por debates de análises políticas historicizadas. A contribuição também se dá no sentido contrário: debates das teorias de RI que podem ser complementados por contribuições históricas na forma de narrativas que assumem suas perspectivas, ao contrário de mera exemplificação supostamente neutra. A transformação do tráfico de escravizados no Atlântico através dos séculos evidencia alteração de uma norma não por causa de mudanças nas práticas, mas em consequência das profundas transformações na política internacional quando da emergência do pensamento liberal europeu. A aporia que provoca este artigo é aquela constitutiva de um período - supostamente - contraditório, em que tanto as ideias de igualdade e liberdade se desenvolveram foi também o período no qual a escravização estava em seu auge, entrelaçada com o capitalismo, e forjando hierarquias no espaço atlântico.

A tentativa de trazer o escravismo atlântico como um processo fundador da política internacional moderna, como uma "instituição" moldada e transformada ao longo dos séculos - nos termos da Escola Inglesa ou através de um questionamento de seus pressupostos eurocêntricos -, é um exercício necessário para tensionar a capacidade analítica dessa abordagem teórica. Por meio disso, buscamos nos alinhar com propostas de leitura do fenômeno do internacional que vão para além da história europeia e do Estado como pressuposto analítico. Como apontado por Alencastro (2000) e Silva (2003), o Atlântico é um espaço de contato, e não de afastamento. Devemos, portanto, encará-lo como um espaço político e histórico, e não como um vazio.

\section{Referências}

AALBERTS, Tanja E.. "Rethinking the Principle of (Sovereign) Equality as a Standard of Civilisation." Millennium: journal of international studies 42 (3), special issue, p. 767- 
789, 2014.

ALENCASTRO, Luiz Felipe de. O Trato dos Viventes: formação do Brasil no Atlântico Sul. São Paulo: Companhia das Letras, 2000.

ALONSO, Angela. Flores, Votos e Balas: o movimento abolicionista brasileiro (186888). São Paulo: Companhia das Letras, 2015.

ANIEVAS, Alexander; NISANCIOGLU, Kerem. How The West Came to Rule: The Geopolitical Origins of Capitalism. London: Pluto Press, 2015.

BALES, Kevin. Disposable People: new slavery in the Global Economy. Berkley, Los Angeles: University of California Press, 1999.

BARTELSON, Jens. A Genealogy of Sovereignty. Cambridge, Cambridge University Press, 1995.

BHAMBRA, Gurminder. Rethinking Modernity: Postcolonialism and the Sociological Imagination. Basingstoke: Palgrave Macmillan, 2007.

BLACKBURN, Robin. The Making of New World Slavery: from the Baroque to the Modern, 1492 - 1800. London: Verso, 1997.

Por Que Segunda Escravidão? In: MARQUESE, Rafael; SALLES, Ricardo (ed).: Escravidão e Capitalismo Histórico no Século XIX: Cuba, Brasil, Estados Unidos. Rio de Janeiro: Civilização Brasileira, 2016, p. 13-54.

BRAUDEL, Fernand. O Mediterrâneo e o Mundo Mediterranico na época de Filipe II. Lisboa: Martins Fontes, 1983.

- Memórias do Mediterrâneo: pré-história e antiguidade. Rio de Janeiro: Multi Nova Distribuidora de Livros Ltda., 2001.

. Civilização Material, Economia e Capitalismo, séculos XV-XVIII.

São Paulo: Martins Fontes, 2009.

Bull, Hedley. The anarchical society: a study of order in world politics. New York: Columbia University Press, 2002.

. The Revolt Against the West. In: BULL, Hedley; WATSON, Adam (ed) The Expansion of International Society. Oxford: Oxford University Press, 1984, p. 217228.

BULL, Hedley; WATSON, Adam. The Expansion of International Society. Oxford: 
Oxford University Press, 1984.

BURCHILL, Scott. Liberalism. In: BURCHILL, Scott et al. (ed).: Theories of International Relations. New York: Palgrave, 1996, p. 29-69.

BURKE, Peter. A Escola dos Annales (1929-1989): a revolução francesa da historiografia. São Paulo: Editora da UNESP, 2010.

BUZAN, Barry; LITTLE, Richard. World History and the Development of non-Western International Relations Theory. In: ACHARYA, Amitav; BUZAN, Barry. Non-Western International Relations Theory: perspectives on and beyond Asia, p.197-220. London: Routledge, 2010.

CAMPBELL, David. Writing Security: United States Foreign Policy and the Politics of Identity. Minneapolis: University of Minnesota Press, 1992.

National Deconstruction: Violence, Identity and Justice in Bosnia.

Minneapolis: University of Minnesota Press, 1998.

CARVALHO, José Murilo de. As Batalhas da Abolição. In: CARVALHO: José Murilo de (ed.) Pontos e Bordados: escritos de história e política. Belo Horizonte: Ed. UFMG, 1998a, p. 35-64.

. Escravidão e Razão Nacional. In: CARVALHO: José Murilo de (ed.) Pontos e Bordados: escritos de história e política. Belo Horizonte: Ed. UFMG, 1998b, p.65-82.

CLARK, Ian. Legitimacy in International Society. Oxford: Oxford University Press, 2005.

CONNERY Christopher L. "Ideologies of land and sea: Alfred Thayer Mahan, Carl Schmitt, and the shaping of global myth elements". In: Boundary 2 28(2), pp.173-201, 2001.

COX, Michael; DUNNE, Tim; BOOTH, Ken (eds). Empires, Systems and States: great transformations in International Politics. Cambridge: Cambridge University Press, 2001.

COX, Robert. "Social Forces, States and World Orders: Beyond International Relations Theory" in Millennium: journal of International Relations, 10 (2), 1981: 126-155.

DAVIS, David Brion. The Problem of Slavery in Western Culture. Oxford: Oxford University Press, 1988.

DOTY, Roxanne Lynn. "The Bounds of "Race" in International Relations." Milleniun: Journal of International Relations. 22 (3) p. 443-461, 1993. 
DUNNE, Tim; REUS-SMIT, Christian. "Introduction". In: DUNNE, Tim; REUS-SMIT, Christian. The Globalization of International Society, Oxford: Oxford University Press, 2017a, p. 3-17.

(ed.). The Globalization of International Society. Oxford: Oxford

University Press, 2017b.

DUZGUN, Eren. "Against Eurocentric Anti-Eurocentrism: International Relations, Historical Sociology and Political Marxism" in Journal of International Relations and Development, 2018, disponível em: https://doi.org/10.1057/s41268-018-0146-0

EPSTEIN, Charlotte. Against International Relations Norms: Postcolonial Perspectives. London, Routledge, 2017.

GILROY, Paul. O Atlântico Negro: modernidade e dupla consciência. São Paulo: Editora 34, 2012.

GONG, Gerrit W. The Standard of 'Civilization' in International Society. Oxford: Clarendon Press, 1984.

GRAHAM, Richard. Britain \& the Onset of Modernization in Brazil (1850-1914). Cambridge: Cambridge University Press, 1968.

JAHN, Beate. Liberal Internationalism: Theory History, Practice. Basingstoke: Palgrave Macmillan, 2013.

JOHNSON, Walter. River of Dark Dreams: slavery and Empire in the cotton kigdom. Cambridge: Harvard University Press, 2013.

JOLL, James. Europe Since 1870: an international history. London: Penguin Books, 1992.

KARP, Matthew. This Vast Southern Empire: slaveholders at the helm of American foreign policy. Cambridge: Harvard University Press, 2016.

KEENE, Edward. Beyond The Anarchical Society: Grotious, colonialism and order in world politics. Cambridge: Cambridge University Press, 2002.

A Case Study of the Construction of International Hierarchy: British Treaty-Making Against the Slave Trade in the Early Nineteenth Century. International Organization 61 (2), p. 311-339, 2007.

. The Standard of 'Civilisation', the Expansion Thesis and the $19^{\text {th }}$ century International Social Space. Millennium: journal of international studies 42 (3), 
special issue, p.651-673, 2014.

KISSINGER, Henry. Diplomacia. Rio de Janeiro: Livraria Francisco Alves, 1997.

LACHER, Hannes. Putting the state in its place: the critique of state-centrism and its limits in Review of International Studies, 29 (4), p. 521-541, 2003.

LINEBAUGH, Peter; REDIKER, Marcus. The Many-Headed Hydra: Sailors, Slaves, Commoners and the Hidden History of the Revolutionary Atlantic. Boston: Beacon Press, 2013.

LINKLATER, Andrew. Violence and Civilization in the Western State-System. Cambridge: Cambridge University Press, 2016.

- Process Sociology, the English School and Postcolonialism Understanding 'civilization' and World Politics: A Reply to the Critics. In: Review of International Studies, 43 (4), p. 700-719, 2017.

LINKLATER, Andrew; SUGANAMI, Hidemi. The English School of International Relations: a contemporary reassessment. Cambridge: Cambridge University Press, 2006.

LOSURDO, Domenico. Liberalism: A Counter-History. London: Verso, 2014.

MACKINDER, Halford. The Geographical Pivot of History. In: The Geographical Journal, 23 (4), 1904: 421-437.

MARQUESE, Rafael; SALLES, Ricardo. A Escravidão no Brasil Oitocentista: história e historiografia. In: MARQUESE, Rafael; SALLES, Ricardo: Escravidão e Capitalismo Histórico no Século XIX: Cuba, Brasil, Estados Unidos. Rio de Janeiro: Civilização Brasileira, 2016, 99-162.

MATIN, Kamran, Redeeming the universal: Postcolonialism and the inner life of Eurocentrism in European Journal of International Relations, 19, p.353-377, 2013.

MATOS, Francisco. Carl Schmitt on the move: spatial politics and the sacrifice of the sea. Tese de Doutorado, Instituto de Relações Internacionais, PUC-Rio. Orientador: Prof. Jimmy Casas Klausen. 2019.

MAYBLIN, Lucy. Never Look Back: political thought and the abolition of slavery Cambridge Review of International Affairs 26(1), p.93-110, 2013.

NEILSON, Brett; ROSSITER, Ned. Precarity as a Political Concept, or, Fordism as Exception. In: Theory, Culture \& Society, 25 (7-8), p. 51-72, 2008. 
OSIANDER, Andreas. Before the State: systemic political change in the West from the Greeks to the French Revolution. Oxford: Oxford University Press, 2007.

PINHEIRO, Letícia; MILANI, Carlos R. S. (orgs.). Política Externa Brasileira: as práticas da política e a política das práticas. Rio de Janeiro: Editora FGV, 2012.

POST, Charles. The American Road to Capitalism: Studies in Class-Structure, Economic Development and Political Conflict, 1620-1877. Leiden: Brill, 2011.

RANDAL, J. G.; DONALD, David. The Civil War and Reconstruction. Boston: D. C. Heath and Company, 1961.

REUS-SMIT, Christian. Individual Rights and the Making of International System. Cambridge: Cambridge University Press, 2013.

. Struggles for Individual Rights and the Expansion of the International System. International Organization 65 (2), p. 217-242, 2011.

. The Moral Pourpose of the State: culture, social identity, and institutional rationality in International Relations. New Jersey: Princeton University Press, 1999.

ROSENAU, James. The Study of World Politics - Volume 1: Theoretical and Methodological Challenges. London: Routledge, 2006a.

The Study of World Politics - Volume 2: Globalization and Governance. London: Routledge, 2006b.

ROSENBERG, Justin. The Empire of Civil Society. London: Verso, 1994.

SALGADO, Pedro. Historia, agencia y eurocentrismo en la Escuela Inglesa. In: Relaciones Internacionales 41: 33-52, 2019a;

Agency and geopolitics: Brazilian formal Independence and the problem of Eurocentrism in international historical sociology. Cambridge Review of International Affairs: disponível em: DOI 10.1080/09557571.2019.1638343, 2019b.

SCHMITT, Carl. The Nomos of the Earth in the International Law of the Jus Publicum Europaeum. New York: Telos Press Publishing, 2003.

SCHMITT, Carl. Land and Sea: A World-Historical Meditation (trans. Zeitlin SG). Candor, NY, Telos Press, 2015.

SCHULZ, Carsten-Andreas. Civilisation, Barbarism, and the Making of Latin America's 
Place in 19th-Century International Society. In: Millennium: journal of international studies, 42 (3), p. 837-859, 2014.

SETH, Sanjay. Postcolonial Theory and the Critique of International Relations. In: Millennium: journal of international studies, 40 (1), p.167-183, 2011.

SHILLIAM, Robbie. The Atlantic as a Vector of Uneven and Combined Development. Cambridge Review of International Affairs, 22:1, p. 69-88, 2009.

. Intervention and Colonial-Modernity: decolonizing the Italy/ Ethiopia conflict through Psalms 68:31. Review of International Studies 39, p. 11311148, 2013.

SCHULZ, Carsten- Andreas. Civilisation, Barbarism and the Making of Latin America's Place in $19^{\text {th }}$-Century International Society. In: Millennium: journal of international studies 42 (3), special issue, p. 837-859, 2014.

SILVA, Alberto da Costa e. Um Rio Chamado Atlântico: a África no Brasil e o Brasil na África. Rio de Janeiro: Nova Fronteira, 2003.

SIMPSON, Gerry. Great Powers and Outlaw States. Cambridge: Cambridge University Press, 2004.STANDING, Guy. The Precariat: the new dangerous class. New York: Bloomsbury, 2011.

STROIKOS, Dimitrios. Introduction: rethinking the standard(s) of civilization(s) in International Relations. In: Millennium: Journal of International Studies 42 (3), special issue, p. 546-556, 2014.

TANSEL, Cemal Burak. Deafening Silence? Marxism, international historical sociology and the spectre of Eurocentrism. In: European Journal of International Relations, 21 (1), p. 76-100, 2015.

THAKUR, Vineet; DAVIS, Alexander E.; VALE, Peter. "Imperial Mission, 'Scientific' Method: an Alternative Account of the Origins of IR". In.: Millenium: Journal of International Studies, 46(1), p. 3-23, 2017.

THOMSON, Janice E. Mercenaries, Pirates, and Sovereigns: State-Building and Extraterritorial Violence in Early Modern Europe. Princeton, Princeton University Press, 1994.

TOMICH, Dale. Through the Prism of Slavery: Labour, Capital, and World Economy. New York: Rowman \& Littlefield Publishers, 2004.

VAINFAS, Ronaldo: Ideologia e Escravidão: os letrados e a sociedade escravista no 
Brasil colonial. Editora Vozes: Petrópolis, 1986.

VAUGHAN-WILLIAMS, Nick, "International Relations and the Problem of History". In.: Millenium: Journal of International Studies 34 (1), p.115-136, 2005.

VINCENT, R. J. Racial Equality. In: BULL, Hedley; WATSON, Adam. The Expansion of International Society. Oxford: Oxford University Press, 1984, p. 239-254.

VITALIS, Robert. White World Order, Black Power Politics: The Birth of American International Relations. Ithaca: Cornell University Press, 2015.

WALLERSTEIN, Immanuel. World-System Analysis: an introduction. Durham: Duke University Press, 2004.

WALTZ, Kenneth, Anarchic Orders and Balances of Power. In: KEOHANE, Robert, O. Neorealism and its critics. New York: Columbia University Press, 1986.

WEAVER, Ole. Four meanings of international society: a trans-Atlantic dialogue. In: ROBERSON, B. A. (ed) International Society and the Development of International Relations Theory. New York: Continuum, 2002, p. 80-144.

WEBER, Cynthia. Simulating Sovereignty: Intervention, the State, and Symbolic Exchange. Cambridge: Cambridge University Press, 1995.

WELSH, Jennifer. Empire and Fragmentation. In: DUNNE, Tim; REUS-SMIT, Christian. The Globalization of International Society, Oxford: Oxford University Press, 2017, p.145-164.

WILLIAMS, Eric. Capitalism and Slavery. Chapel Hill: The University of North Carolina Press, 1944.

YAMATO, Roberto Vilchez. Rastreando o Fora-da-Lei da Humanidade: Um estudo sobre a Política Internacional de Banimento a partir de Memorandos Norte-Americanos da "Guerra Contra o Terror". Tese de Doutorado, Instituto de Relações Internacionais, PUC-Rio. Orientador: Prof. João Pontes Nogueira. Disponível em: https://www.maxwell.vrac.puc-rio.br/37977/37977_1.PDF, 2011.

YAMATO, Roberto Vilchez. Beyond the line: Carl Schmitt and the constitutive outsider of the international. Politics 39(2), pp. 218-232, 2019.

YAMATO, Roberto Vilchez. Reading Schmitt from the sea: tracing constitutive outsiders and displacing the conceptual order (and ordering) of the political. DADOS Revista de Ciências Sociais, 2020 (no prelo). 